Yury Goryachev,

Ph.D in History, Scientific supervisor of the UNESCO Chair «International Education and the Integration of Migrants» of the Moscow Pedagogical State University, Scientific editor of the almanac «Ethnodialogy», unescochair-gor@yandex.ru

\section{Vladimir Zakharov,}

Leading specialist, Faculty of regional studies and ethnocultural education, Institute of Social and Humanitarian Education, Moscow Pedagogical State University, vfzakharov@mail.ru

\section{On the Way towards International Standards of Education}

In this edition of the almanac «Ethnodialogy» the third, and final, part of the article «Towards international standards of education: from pedagogy of early thinkers to modern approaches» is published. The article is prepared by the specialists of the Faculty of regional studies and ethnocultural education of the Moscow Pedagogical State University. It tells us about the contribution of the ideas of the great Russian scientists M.V. Lomonosov, V.I. Vernadsky, K.E. Tsiolkovsky, and others to the formation of the Global worldview. Both the process of development of the Common educational environment and the International standard classification of education are presented in the article.

Speaking about the modern globalization at the turn of the millennium, the authors note the growing interdependence of the world - economic, sociocultural, and political. Special attention is paid to its role in the development of integration processes in education, including the formation of a common Eurasian educational space by the Russian Federation together with other members of the CIS, the EAEU, the Asia-Pacific region, and the SCO; the consolidation of agreements on a pan-European educational space within the framework of the Bologna Process; the adoption, with the assistance of UNESCO, of the regional conventions for the recognition of qualifications in higher education in Africa, Asia and the Pacific, the Arab East, the Mediterranean and Latin America. And, finally, the adoption of the first internationallegal instrument in the UN system in the field of education with a global scope - the Global Convention on the Recognition of Qualifications concerning Higher Education. The article is followed by the Supplement «The main international legalacts in the field of education».

Keywords: Global Convention on the Recognition of Qualifications concerning Higher Education; Bologna Process; Copenhagen Process; Asia-Pacific Convention on the Recognition of Higher Education Qualifications; Shanghai Cooperation Organization (SCO), Eurasian Economic Union (EEU), Commonwealth of Independent States; International Standard Classification of Education (UNESCO ISCED); Eurasian educational space; European integration of higher education; sustainable development; globalization, convention, declaration.
В декабре 2020 г. в Московском педагогическом государственном университете состоялся международный научно-практический семинар «Международное образование и интеграция: новые вызовы и решения». XII семинар из цикла «Диалог цивилизаций и межкультурное сотрудничество» приурочен к юбилейным мероприятиям в год 75-летия ООН и ЮНЕСКО. Альманах «Этнодиалоги» будет знакомить своих читателей с докладами, сделанными на семинаре.

\section{Людмила Баева}

\section{Образование для социальной устойчивости перед лицом вызовов XXI века}

Достижение целей устойчивого развития, принятых во всем мире на основе международных соглашений ООН и ЮНЕСКО, тесно связаны с системой образования, призванной формировать мировоззрение и навыки для осознания взаимосвязи человека с обществом и окружающей средой. Повестка устойчивого развития в мире находится в состоянии постоянного расширения поля охвата проблем по мере возникновения новых вызовов обществу. В статье представлен анализ включения в стратегию устойчивого развития вопросов, возникших в условиях миграционного кризиса в Европе, а также анализ актуальных вопросов, вызванных пандемией COVID-19 и форсированным переходом к цифровому образованию в мире. Отмечено, что этот переход затрагивает не только технологические, методические и кадровые ресурсы, но также связан с вопросами социальной устойчивости. С позиции теории безопасности основные проблемы в реализации этого процесса оказываются связанными с технологическими, витальными, адаптивными, аддиктивными, социальными рисками. Одним из рисков выступает ослабление навыков социальной коммуникации, солидарности, умения взаимодействовать в мультикультурной среде, что требует профилактических мер и специализированных курсов в учебных планах.

This article was prepared as part of the project 611528-EPP-1-2019-1-RU- EPPJMOMODULE, that has been funded with support from the European Commission. This publication reflects the views only of the author, and the Commission cannot be held responsible for any use which may be made of the information contained therein.

Ключевые слова: устойчивое развитие; образование; вызовы; миграционный кризис в Европе; COVID-19; цифровая трансформация образования. 


\section{Устойчивое развитие как стратегия динамики современного социума}

Вопросы социальной устойчивости в мире на протяжении последних десятилетий прочно входят в основную повестку дня. На смену ценности прогресса и сверхбыстрого роста экономики, природопользовании и иных областях жизни в системе современных приоритетов закрепилась ценностная установка на социальную устойчивость как состояние, при котором затрачиваемые ресурсы не наносят необратимого ущерба природе и позволяют ее сохранить для будущих поколений. От экологической повестки тема устойчивого развития расширялась до широкого спектра экономических, социально-политических, демографических проблем. В настоящее время стратегия устойчивости в мире воспринимается как совокупность действий, подходов, установок и ценностей, способных обеспечить сбалансированное решение проблем социального, эколого-экономического развития и сохранения окружающей среды, удовлетворение потребностей

\section{Баева}

Людмила Владимировна

доктор философских наук, профессор, декан факультета социальных коммуникаций, Астраханский государственный университет (Астрахань) baevaludmila@mail.ru настоящего и будущего поколений [1]. Достижение устойчивого развития в современном контексте определяется прежде всего решением актуальных социальных проблем, улучшением качества жизни человека, гарантией прав и свобод личности, вовлечением гражданского общества в управление своей жизнью.

В качестве одного из важных механизмом обеспечения устойчивого социального-экономического и духовного развития во всем мире признано образование, поскольку именно оно формирует ценностные установки будущих поколений граждан, с одной стороны, а с другой - является важнейшим социальным институтом, касающимся практически каждого. Вопросы определяющей роли образования отмечались еще в материалах всемирного саммита по устойчивому развитию в Йоханнесбурге в 2002 г., где оно рассматривается как сфера, определяющая пути развития личности в отношении окружающей среды и способствующая изменению системы ценностей, приоритетов, идеалов общества с целью коренного преобразования цивилизации. Оно представляет собой целостную систему, охватывающую всю жизнь человека, с целью формирования его мировоззрения [2]. Участники саммита приняли решение утвердить программу по образованию для XXI века на ближайшее десятилетие (2005-2014). Главной целью этой программы была заявлена интеграция принципов, ценностей и опыта в области устойчивого развития во все аспекты образования и просвещения. В программе подчеркивалось, что совершенствование образования с учетом идей устойчивого развития будет содействовать изменениям в поведении людей во всех странах и на всех континентах и позволит создать условия для более устойчивого будущего, характеризуемого чистотой окружающей среды, экономической стабильностью и справедливостью по отношению к современному и последующим поколениям [2].

В странах Евросоюза большую роль для развития системы образования играет «Стратегия образования 
в интересах устойчивого развития», принятая на конференции Европейской экономической Комиссии ООН в 2013 г. в Женеве. Цель стратегии состоит в том, чтобы «вооружить людей знаниями и навыками в области устойчивого развития, сделав их более компетентными и уверенными, в то же время увеличивая их возможности для ведения здорового и продуктивного образа жизни в гармонии с природой и с заботой о социальных ценностях, гендерном равенстве и культурном разнообразии» [7]. На этой конференции ООН был принят целый ряд важных документов, утверждающих подходы к обучению, а также инструментарий для педагогов.

В документе «Расширение возможностей преподавателей в интересах устойчивого будущего», разработанном Европейской экономической комиссией Организации Объединенных Наций, отмечено, что образование в обучение устойчивому развитию (ОУР) следует рассматривать как процесс адаптации целостного подхода к предвидению изменений, обеспечивая тем самым достижение преобразований, это требует от преподавателей специальных знаний и педагогических навыков. Однако, отмечается в документе, формировать нужно не только знания и умения. Образование и устойчивое развитие рассматриваются через призму необходимости взаимодействия с другими людьми, в связи с этим подчеркивается необходимость особых умений педагогов, в том числе связанных с его мировоззрением совокупностью его личностных качеств. [7, с. 2] На конференции в Женеве был выработан перечень компетенций, которые связаны с обучением устойчивому развитию и касаются как самих педагогов, так и учащихся. В их основе лежит интеграционное мышление, включающее основы системного мышления, понимание взаи- мосвязей природных, социальных и экономических систем, осознание связей внутри нынешнего поколения и между поколениями, между людьми и природой, между представителями различных культурных традиций и форм мировоззрения. Большую роль для ОУР играет умение предвидеть изменения и готовность реагировать на них, умение принимать решения с «опорой на научные доказательств как средства поддержки устойчивого развития», важность постановки проблем, критического осмысления, предвидения и творческого мышления при планировании будущего и осуществлении преобразований [7, с. 11].

Принятые документы в области образования были призваны подготовить общество к возможным вызовам и неопределенности, что оказалось чрезвычайно необходимым в последующие годы.

\section{Миграционный кризис в Европе как вызов социальной устойчивости}

Проблемы поддержания социальной устойчивости оказались чрезвычайно актуальными в условиях последующих вызовов, которые встали перед европейским сообществом и человечеством в целом. Для развития европейской культуры одним из значимых вызовов, необратимо изменивших жизнь, стал миграционный кризис, крупнейший со времен Второй мировой войны. За 2015 г. из-за военных конфликтов в Африке и на Ближнем Востоке в западноевропейские страны въехало по разным оценкам от 1 до 1,8 млн мигрантов, вынужденных искать безопасное место проживания и более высокое качество жизни. Миграционный кризис породил разнообразные последствия, в том числе он стал катализатором социальной неустойчивости, рискогенности в стабильной экономике и социальной 
практике в Европе. Для экономического развития стан EC, особенно для южных, наиболее слабых из них, приток мигрантов стал тяжким бременем. Для наиболее богатых стран, прежде всего Германии и Франции, миграционный кризис обозначил не столько экономические, сколько социальные вызовы.

Значительная доля мигрантов в составе населения европейских городов, не стремящаяся к ассимиляции и аккультурации, стала играть все более активную роль в обществе, в том числе и конфликтогенную. На протяжении ряда лет европейские страны оказались в ситуации постоянного противостояния ценностных систем: либеральной и традиционалистской. Западноевропейский либерализм с установками на постматериальные ценности, демократию, разнообразие, терпимость, права человека вступил в противостояние с системой ценностей традиционного мировоззрения, в основе которого лежат коллективизм, религиозная вера, нетерпимость, материальные ценности, ценности выживания. Эта ситуация потребовала значительных усилий для стабилизации, принцип устойчивости стал актуальным прежде всего в сфере межкультурных взаимодействий. Миграционный кризис показал отсутствие солидарности стран в подходах в отношении беженцев и мигрантов, вызвал раскол в странах Шенгенского соглашения, стал одной из важнейших причин выхода Великобритании из состава ЕC, а также вызвал волну экстремизма и социальную напряженность в европейских городах, а главное, стал гуманитарной катастрофой для самих беженцев и их детей. Социальная устойчивость в этот момент оказалась чрезвычайно уязвимой.

Курс на устойчивое развитие для современного социума определила декларация, принятая на Генеральной ассамблее ООН в 2015 г. «Преобразование нашего мира: повестка дня в области устойчивого развития на период до 2030 года», в котором получили отражение 17 целей и 169 задач, обеспечивающих баланс трех направлений устойчивого развития: экономического, социального и экологического [3]. Понимание устойчивого развития расширяется: декларация «также предусматривает построение более миролюбивого и свободного от социальных барьеров общества» [3, с. 7]. Ситуация, сложившаяся в результате миграционных волн, также нашла отражение в декларации: «Мы признаем позитивный вклад мигрантов в обеспечение всеохватного роста и устойчивого развития. Мы также признаем, что международная миграция представляет собой многоплановое явление, имеющее большое значение для развития стран происхождения, транзита и назначения и требующее применения согласованного и всеобъемлющего подхода» [3, с. 10]. Среди 17 целей устойчивого развития (ЦУР) четвертая цель связана с образованием: «Обеспечение всеохватного и справедливого качественного образования и поощрение возможности обучения на протяжении всей жизни для всех» [3, с. 17]. Вопросы образования, его доступности для детей мигрантов в европейских странах оказались чрезвычайно острыми и находятся в центре внимания с 2015 года.

В этих сложных условиях были выработаны новые подходы для системы образования с учетом фактора миграционных потоков в Европу. Одним из важнейших документов в этой сфере стал Всемирный доклад по мониторингу образования ЮНЕСКО в 2019 г. «Мигранты, перемещенные лица и образование: наводить мосты, а не возводить препятствия» [5]. В докладе отмечалось, что систему обучения в Европе необходимо адаптировать с учетом новых вызовов. Недостаточно позволить детям мигрантов просто включиться в существующую систему обучения, но необходимо создать более гибкую 
систему образования с учетом прибывающих мигрантов, где они бы не чувствовали дискриминации, а учителя обладали бы навыками работы с ними. Изменения в системе образования призваны снизить социальную напряженность в настоящем и будущем: «Смысл этого доклада очевиден: инвестирование в образование мигрантов превращает путь к неудовлетворенности и волнениям в путь к сплоченности и миру» $[5$, с. 7].

Новая система образования должна стать инклюзивной по своему характеру и выполнять свои обязательства в отношении обеспечения справедливости: «Учителей следует готовить к работе в классах с разнообразным составом учащихся, перенесших травму в связи с миграцией и, особенно, перемещением... Рост разнообразия учащихся в классе сопряжен с вызовами, в том числе для местных жителей (в особенности бедных и маргинальных), но он также предлагает возможности для того, чтобы учиться у других культур, у людей с иным опытом. Как никогда ощущается потребность в учебных программах, способных бороться с негативными жизненными установками» [5, с. 12]. При этом в мониторинге был представлен реалистичный ситуативный анализ возникающих в связи с миграцией проблем в сфере образования, анализ бюрократических, языковых, правовых и иных ограничений, создающих преграды для получения качественного образования детей в различных странах и экономических условиях.

Следует отметить, что рекомендации ООН и ЮНЕСКО в области обучения мигрантов ориентируют правительства стран на инклюзивное обучение детей мигрантов, обеспечение их прав и свобод наравне с другими гражданами, а не на сегрегированное образование. В новых условиях для педагогов чрезвычайно важны социокультурные компетенции, навыки межкультурного, межконфессионального диалога, умение работать с детьми с посттравматическими стрессовыми расстройствами, нуждающимися в психологической поддержке, с плохим знанием (либо незнанием) языка обучения. Этот вызов показал, что даже социально устойчивые и благополучные страны могут оказаться в ситуации неустойчивости и кризиса; система образования выполняет роль стабилизатора социальной устойчивости и имеет важную социальную миссию; что межкультурное взаимодействие становится новой реальностью и требует постоянного учета при планировании решений; что обеспечение прав личности остается важнейшим приоритетом устойчивого развития, даже в условиях социальных трансформаций.

\section{«Черный лебедь» COVID-19 как вызов социальной устойчивости}

2020 год оказался для мира связанным с новым вызовом, пандемией COVID-19, подобно «черному лебедю» M. Талеба ставшего точкой невозврата для общества [4]. Непрогнозируемый, неуправляемый, охвативший практически все человечество, изменивший жизнь каждого, он заставил пересмотреть многие определяющие жизнь нормы и порядки. Прежде всего новые ограничения оказались связаны с коммуникацией и контактным общением, что привело к необходимости перевода работающих на удаленную работу, а учащихся на дистанционный формат обучения. Межличностные отношения практически полностью переместились в цифровую среду. Информационные технологии в этих условиях создали возможность осуществлять непрерывную трудовую деятельность для многих отраслей экономики, хотя ряд из них, к сожалению, стали жертвами локдауна. Образование в этих беспрецедентных условиях было переведено в дистанционную форму работы в различных видах, и остается таковым для многих стран 
и крупных городов. Пандемия стала мощным вызовом социальной устойчивости, показав, что жизнь человека все еще подвержена высоким рискам, а экономический рост и благополучие не гарантированы даже в развитых странах.

Система образования до 2020 г. уже была отчасти на пути цифровой трансформации, однако это был «небольшой остров» в море традиционного обучения. В 2020-м цифровое образование стало общей практикой. После цифрового поворота система образования в школах и вузах оказалась в условиях беспрецедентного эксперимента, позволившего сделать важные выводы о влиянии цифровизации на образование. Цифровое образование позволило сохранить непрерывность обучения на всех уровнях, хотя проблема информационного неравенства и доступа к ресурсам все же возникла. Особенно это коснулось многодетных семей, где не у каждого ребенка был собственный гаджет для учебы, а также для малообеспеченных граждан и людей, проживающих в отдаленных районах, из-за проблем с высокоскоростным интернетом.

Цифровое обучение из временной меры стало новым социальным трендом, интенцией необратимого действия, в силу чего возникла необходимость изучения его возможных социальных последствий и характера влияния на человека. Прежде всего цифровое образование обеспечило безопасность его субъектов в условиях распространения заболеваемости. Однако обучение было переведено в особую виртуальную среду коммуникации, имеющую свои особенности и риски, в одной стороны, связанные с высоким уровнем киберугроз, с другой - отличающуюся высоким плюрализмом, отсутствием жестких нормативных границ. Вопросы безопасности в сфере цифрового образования для стран ЕС были рассмотрены среди важнейших на III Ев- ропейском образовательном саммите (12.12.2020), где в качестве одной из задач Европейской комиссии было названо развитие цифровых компетенций и повышение информационной грамотности населения. На саммите был принят «План действий в области цифрового образования (2021-2027)», в котором в том числе были отмечены возникшие в период 2020 г. проблемы цифрового образования. Усилия по сдерживанию вспышки COVID-19 привели закрытию университетов и учебных зданий, кампусов и других объектов и вынужденному переходу на чрезвычайные режимы цифрового образования. Эти чрезвычайные режимы включали широкое использование онлайн- и дистанционного обучения. Это массовое и беспрецедентное использование технологий в обучении открыло перед учителями множество возможностей по-разному организовать педагогический процесс, взаимодействовать со студентами на более персонализированной основе, учитывая их конкретные потребности. В то же время многие государства столкнулись с недостатками в этой системе и широко распространенным отсутствием доступа к ресурсам, оборудования, связи или навыков. В некоторых странах подавляющее большинство преподавателей и учащихся почти не имели опыта преподавания в цифровой среде [6].

Среди существенных проблем, связанных с цифровым обучением, отмечались следующие: наиболее уязвимыми оказались младшие и средние школьники, которые сами не могли организовать свой процесс обучения, если родители имели высшее образование, учебный процесс детей был организован успешнее, детям была оказана необходимая помощь, использование экрана в течение всего дня влияет на концентрацию и может отрицательно сказаться на психическом благополучии; актуализировалась защита личных данных [6]. В качестве главного направления деятельности Ев- 
ропейской Комиссии указана разработка «общих руководящих принципов для учителей и педагогического персонала по повышению цифровой грамотности и борьбе с дезинформацией посредством образования и обучения» [6].

Данные проведенного массового опроса об отношении населения к онлайн-обучению в условиях пандемии показали, что основными областями, вызывающими озабоченность респондентов, были вопросы обеспечения доступа, равенства и инклюзивности. Лица с ОВЗ также сообщали о трудностях: о доступности технологий и цифровых учебных материалов, о наличии вспомогательных технологий, о технической поддержке, оказываемой учащимся-инвалидам, и о компетентности учителя в вопросах инвалидности и доступности. Поставщики обучения для взрослых видели большое количество студентов, бросающих курсы, в некоторых случаях оставляли занятия три четверти группы.

В течение 2020 года нами также были проведены фокус-групповые опросы педагогов относительно проблем, с которыми они столкнулись в этот период, и возможных последующих рисков цифровой трансформации обучения. Полученные данные показали, что помимо существенных достоинств цифрового обучения с ним связаны новые проблемы безопасной коммуникации в электронной образовательной среде, общее ослабление качества обучения:

1. Ухудшение когнитивных навыков, связанное с системой подачи информации, представленной в готовом (не требующем анализа и обработки) упрощенном для восприятия виде, снижение результатов обучения, способностей к творчеству, самостоятельнойвербальной презентации знаний, аналитических, критических, логических навыков мышления.
2. Ослабление роли межличностной коммуникации, социальных навыков (диалога, взаимопомощи, ответственности, вовлеченности, работы в командах, лидерства и др.), связанных с виртуализацией общения и обучения.

3. Рост рисков ухудшения параметров здорового образа жизни из-за многочасовой работы у экранов.

4. Усиление общей растущей зависимости от гаджетов и интернет-коммуникации. Полный переход среды обучения в цифровое пространство может усилить зависимости от сетевой коммуникации, не только адаптируя человека к цифровой среде, но и делая его несвободным от нее.

5. Определенные угрозы безопасности личности, связанные с нарушением прав человека в цифровой среде, в том числе авторских прав, чести и достоинства, конфиденциальности и др.

6. Рост угроз кибератак, кибермошенничества, распространения фейковой информации в цифровой среде.

7. Усиление рисков киберзапугивания, вовлечения в деструктивные виртуальные сообщества, манипулирования сознанием и т. д.

Каждый из рисков представляет собой комплекс разнообразных угроз, которые могут активироваться при наличии тех или иных уязвимостей, усиливающихся в зависимости от групп риска. В связи с этим развитие цифровой среды в системе образования должно учитывать оценку степени тех или иных угроз для физического и душевного здоровья личности и быть ориентированным на создание безопасной информационно-коммуникативной образовательной среды, включающей информационно-технологическую, этическую, коммуникационную, психологическую и иные составляющие. 
В современном обществе осуществляются значительные по масштабам и беспрецедентности изменения, касающиеся перехода системы образования в цифровую среду, что связано и с вопросами социальной устойчивости в будущем. Эти процессы будут сопровождаться изменениями как в социальной, правовой, так и в методологической и методической областях, чтобы обеспечить безопасность и эффективность этого процесса для учащихся. Для реализации этих планов необходимо научное прогнозирование и анализ возможных последствий и перспектив, в том числе анализ рисков и угроз в различных сферах. Проведенный прогностический анализ показывает, что наиболее существенные риски могут быть связаны с дисфункциями либо дезориентацией личности в коммуникативной, когнитивной, этико-нормативной, духовно-патриотической сферах. Существенное воздействие цифровизация образования может оказать и на физические параметры здоровья, увеличив экранное время, под угрозой также могут оказаться социальные навыки. Эти риски и угрозы могут быть дополнены, если рассматривать эту проблему с позиции информационной безопасности, где негативное влияние может быть связано с использованием больших данных, персональной информации, с кибератаками и кибермошенничеством. Изучение этих рисков приводит к необходимости формирования планов цифровой трансформации с учетом профилактики этих возможных негативных последствий, поскольку они не только могут снизить успех цифрового обучения, но и оказать влияние на навыки будущего поколения.

В этих условиях мы предлагаем для изучения свой опыт работы для сохранения навыков межкультурной коммуникации и осознания целей устойчивого развития. В Астраханском государственном университете в учебные планы бакалавров включена дисциплина «Духовно-нравственные проблемы современного-человека и общества», цель которой - усвоение принципов гуманизма и духовно-нравственных ценностей для развития личности, формирование навыков межкультурного диалога. Также в учебные планы магистров гуманитарных направлений и социологов включена дисциплина «Стратегия устойчивого развития», цель которой формирование мировоззрения и ценностей с учетом ориентира на устойчивое развитие, изучение опыта стран ЕС и мира в осуществлении целей и задач для обучения устойчивому развитию.

В условиях современных многомерных вызовов, каждый из которых способен поставить человечество на колени, образование призвано стать одним из факторов стабилизации общества и повышения его устойчивости. Поэтому сама система образования, даже в условиях ее технологической трансформации, должна быть сохранена не только как передача знаний и информации, но и как система формирования ценностей и смыслов для будущих поколений.

\section{Лumepamypa:}

1. Брундтланд Г.Х. Наше общее будущее // Доклад $0 \mathrm{OH}$ по окружающей среде и развитию. 1987. М.: Прогресс, 1988. URL: https://www.un.org/ru/ga/pdf/brundtland. pdf (дата обращения: 21.01.2021).

2. Йоханнесбургский меморандум. Справедливость в хрупком мире. М.: ОГИ, 2002. 86 c.

3. Преобразование нашего мира: Повестка дня в области устойчивого развития на период до 2030 года. Женева, 2015. URL: https://www.un.org/ga/search/view_doc. asp?symbol=A/RES/70/1\&Lang=R (дата обращения: 21.01.2021)

4. Талеб Н. Черный лебедь. Под знаком непредсказуемости. М.: КоЛибри, 2015. 736 с.

5. ЮНЕСКО. Резюме всемирного доклада по мониторингу образования 2019 г.: Мигранты, перемещенные лица и образование: наводить мосты, а не возводить препятствия. Париж, ЮНЕСКО. 2019. URL: https://reliefweb.int/sites/reliefweb.int/ files/resources/265996r.pdf 
6. Digital Education Action Plan (2021-2027) Брюссель, 2020. URL: https://ec.europa. eu/education/education-in-the-eu/digital-education-action-plan_en (дата обращения: 21.01.2021).

7. Education for Sustainable Development. Женева, 2013. URL: https://unece.org/ environment-policy/education-sustainable-development (дата обращения: 21.01.2021).

\section{Lyudmila Baeva,}

Doctor of Philosophy, Professor, Dean of the Faculty of social communications,

Astrakhan State University (Astrakhan),

baevaludmila@mail.ru

\section{Education for social sustainability in the face of the challenges of the 21st century}

The achievement of the Sustainable Development Goals, adopted worldwide on the base of the United Nations and UNESCO international agreements, is linked to the education system, which is designed to form a worldview and skills for understanding the relationship of man with society and the environment. The world's sustainable development agenda is in a state of constant expansion of the scope of problems as new challenges to society arise. The article presents an analysis of how to include in the sustainable development strategy the issues that arose in the context of the migration crisis in Europe, as well as an analysis of topical issues caused by the COVID-19 pandemic and the forced transition to digital education in the world. It is noted that this transition affects not only technological, methodological, and human resources, but also related to issues of social sustainability. From the perspective of security theory, the main problems in the implementation of this process are associated with technological, vital, adaptive, addictive, and social risks. One of the risks is the weakening of social communication skills, solidarity, and the ability to interact in a multicultural environment, which requires preventive measures and specialized courses in the curriculum.

This article was prepared as part of the project 611528-EPP-1-2019-1-RU-EPPJMOMODULE, that has been funded with support from the European Commission. This publication reflects the views only of the author, and the Commission cannot be held responsible for any use which may be made of the information contained therein.

Keywords: sustainable development; education; challenges; migration crisis in Europe; COVID-19; digital transformation of education.

\section{Танзиля Нигматуллина}

\section{Архитектура исторического образования: вызовы времени}

Актуальность статьи определяется необходимостью изменения системы исторического образования в стране, обусловленная вызовами времени. Особое внимание уделяется причинам, которые приводят к снижению интереса обучающихся к истории, а также проблемам исторического образования в мире в целом. Автор анализирует результаты социологического опроса, лучшие практики вуза, направленные на сохранение исторической памяти, формирование в детской и молодежной среде общероссийской гражданской идентичности, нравственно-этических иенностей и активной жизненной позиции, воспитание бережного и уважительного отношения к историческому и культурному наследию народов Российской Федерации и мира.

Ключевые слова: историческое образование; историческое сознание; фолк-хистори; псевдоистория; программа «Обсерватория»; гражданственность; проектная работа; история в вузе.

Без памяти - нет истории, без истории - нет культуры, без культуры - нет духовности, без духовности - нет воспитания, без воспитания - нет че ловека, без человека - нет народа.

В.А. Караковский, илен-корреспондент РАO, лауреат премии Президента Российской Федераиии, народный учитель СССР

\section{Нигматуллина}

\section{Танзиля Алтафовна,}

доктор политических наук,

дочент; директор, заведующая кафедрой политологии,

истории, теории государства

и права Башкирского института социальных

технологий (филиала)

образовательного учреждения профсоюзов высшего

образования «Академия труда

и социальных отношений» (Уфa),vova-velc@yandex.ru
Значимость исторического образования для формирования личностных качеств детей и молодежи, их гражданской позиции, патриотизма, ответственности за происходящее сегодня ни у кого не вызывает сомнения. Вместе с тем интерес к истории у подрастающего поколения снижается, о чем свидетельствуют многочисленные социологические опросы и тот факт, что уровень знаний обучающихся в рамках этого предмета далеко не всегда соот- 